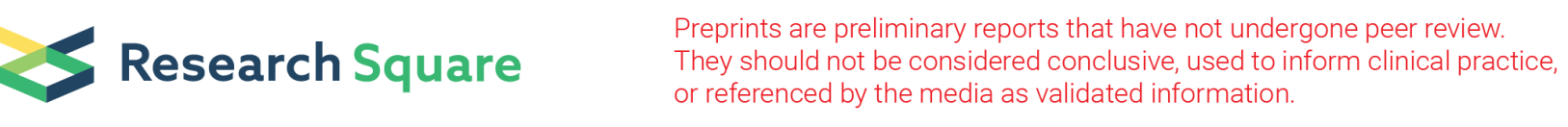

\title{
New model could help make metal alloys even stronger
}

Arvind R. Kalidindi

Christopher A. Schuh

\section{Video Abstract}

Keywords: Journal of Materials Research, Massachusetts Institute of Technology, phase transition, nanocrystal, alloy, nanocrystalline alloy, segregation, grain boundary, Monte Carlo simulation, enthalpy, grain size, grain refinement, phase diagram, entropy, configuration space, grain boundary network, free energy, bicrystal, grain boundary engineering, strengthening

Posted Date: September 23rd, 2019

DOI: https://doi.org/10.21203/rs.2.14970/v2

License: (c) (i) This work is licensed under a Creative Commons Attribution 4.0 International License.

Read Full License 


\section{Abstract}

As materials scientists know well, one reliable way to make strong metals even stronger is to shrink their already-tiny crystalline grains. It's a time-tested technique that's made today's cars, planes, and armor safer than ever. But at the nanoscale, grains are notoriously fickle. Their strong tendency to grow makes it nearly impossible for researchers to chase higher levels of strength. But that could soon change. A new computer model developed by researchers from MIT shows how nano-sized grains might be stabilized in metal alloys. Their findings could provide the blueprint for constructing harder and stronger metals. Alloying one metal with another is one technique that has helped researchers push grain sizes to smaller and smaller scales-thanks to a process known as segregation. As the grains in a metal shrink, the addition of a small amount of an alloying metal segregate, or adhere, to the boundaries between different grains. Like police officers containing an unruly crowd, these secondary atoms keep grains from growing out of control. The thermodynamics of this process are well understood for relatively large grains. There are libraries of maps that tell metal-makers how to achieve the desired strength or hardness. But no such maps are available for alloys made up of nano-sized grains. The problem is a poor grasp of how nanograins in alloys behave under real conditions, which naturally involve fluctuations in temperature: How do policing atoms corral an increasingly disorderly crowd? Most models treat these enforcers individually. That tends to make calculations easy to perform. But it comes at the expense of producing results that aren't exactly true to life. To tackle this problem, the MIT researchers built a simulation model that treats the full network of enforcers as a material all its own. The result is the kind of two-phase system that materials researchers are used to working with. As such, the researchers could create phase maps that predict the conditions that give rise to stable nanograins of various sizes. This new approach isn't perfect. For one, the resolution of the model could be improved to capture smaller changes in grain structure with rising temperature. And it remains to be seen how the phase maps translate into real materials in the lab. But with further improvements, the new method could be a useful tool for creating stronger metal alloys. 